\title{
The Prevalence of Helicobacter Pylori babA, homB, aspA, and sabA Genes and Its Relationship with Clinical Outcomes in Turkey
}

\author{
Nimet Yılmaz $\mathbb{D}^{1}$ and Meltem Koruk Özer $\mathbb{D}^{2}$ \\ ${ }^{1}$ University of SANKO, Faculty of Medicine, Department of Internal Medicine, Division of Gastroenterology, \\ 27310 Sehitkamil, Gaziantep, Turkey \\ ${ }^{2}$ Medical Biology and Genetics Department, Health Sciences Institute, University of Gaziantep, Turkey
}

Correspondence should be addressed to Nimet Yılmaz; nyilmaz@sankotip.com

Received 27 March 2019; Accepted 23 May 2019; Published 13 June 2019

Academic Editor: Maikel P. Peppelenbosch

Copyright (C) 2019 Nimet Yllmaz and Meltem Koruk Özer. This is an open access article distributed under the Creative Commons Attribution License, which permits unrestricted use, distribution, and reproduction in any medium, provided the original work is properly cited.

Background and Aims. The cag A and vac A genes of Helicobacter pylori (H. pylori) are closely associated with the pathogenicity of bacteria. However, the significance of $\mathrm{H}$. pylori $b a b A$, homB, aspA, and sabA genes is not clear in phenotypic characteristics of virulence. This study aimed to investigate the frequency and importance of these genes in patients with $\mathrm{H}$. pylori positive peptic ulcer (PU). Materials and Methods. Patients with a PU or nonulcer dyspepsia (NUD) based on the upper gastrointestinal (UGI) endoscopy findings were included in the study. Biopsy samples from antrum and corpus were cultured into Columbia agar. $H p y l o r i$ were characterized by urease, catalase, oxidase test, and gram staining. Genomic DNA was extracted and stored. The $b a b A$, homB, $a s p A$, and $s a b A$ genes were determined by using polymerase chain reaction analysis. Results. A total 214 patients were included (99 PU and $115 \mathrm{NUD}$ ) and $\mathrm{H}$. pylori could be isolated in 82 patients (36 PU and $46 \mathrm{NUD}$ ). The frequency of the $b a b A$ ( $25 \%$ vs. $15.2 \%, \mathrm{p}=0.25)$, homB ( $2.7 \%$ vs. $4.3 \%, \mathrm{p}=1)$, aspA ( $69.4 \%$ vs. $73.9 \%, \mathrm{p}=0.2)$, and $s a b A(2.7 \%$ vs. $10.8 \%, \mathrm{p}=0.88)$ genotypes was not different between PU and NUD patients. There were some correlations between the presences of these genes. Conclusion. This study managed to determine $b a b A$, homB, aspA, and sabA genes of $\mathrm{H}$. pylori by PCR. However, the frequency of these factors was not different in patients with PU and NUD. There is no role of $b a b A$, homB, aspA, and sabA genes for the development of peptic ulcer in Turkish population.

\section{Introduction}

Helicobacter pylori (H. pylori) is a gram-negative, spiralshaped, 4-6-flagellated mobile bacterium that grows in the digestive tract and microaerophilic environment at $37^{\circ} \mathrm{C}$ in culture. The coccoid form of $\mathrm{H}$. pylori is also called sleeping form. H. pylori produces urease that catalyzes the hydrolysis of urea to yield ammonia and carbonic acid. Flagella, urease, and adhesins are all essential factors for $\mathrm{H}$. pylori to colonize the gastric mucosa [1].

$H$. pylori may be present in almost half of the world population. The incidence of $H$. pylori infection varies according to gender, race, and social and socioeconomic status of the population. The people who are living in developing countries are very commonly infected with $H$. pylori whereas the frequency of H. pylori infection is rare in Australia, Canada, and the USA [2]. The occurrences of new gastric cancer cases were variable in developing countries $(8.4 \%)$ and developed countries (4.5\%) [3]. Gastrointestinal cancer-related death rate is the third most common cause of all cancer-related deaths. H. pylori are correlated with the development of duodenal ulcer and gastric cancer. H. pylori infected individuals are having risk of developing peptic ulcer in $15-20 \%$, gastric cancer in $1 \%$, and primary gastric lymphoma in $0.1 \%$. H. pylori infection is a high risk factor for the development of peptic ulcer, gastric maltoma, and adenocarcinoma [4]. Therefore, it may cause significant health problems. The transmission way of $H$. pylori has not been fully clear, yet [5].

H. pylori are adapted and colonize harsh, acidic environment of the stomach and survive in acidic environment that 
causes induction of gastritis, peptic ulcer, or gastric cancer. $H$. pylori is actually an opportunistic pathogen. Some virulence factors of $H$. pylori, such as $\operatorname{cag} A$ and $v a c A$, are the most pathogenic factors among all virulence factors [6]. There are also some other genes of $H$. pylori such as babA, homB, aspA, and $s a b A$ the significance for pathogenicity of which is not clear yet.

H. pylori adhesions such as the Lewis blood group antigen-binding adhesion $(b a b A)$ and the sialic acid-binding adhesion $(s a b A)$ are considered to have a significant function on initial colonization of $H$. pylori $[7,8]$.

H. pylori outer-membrane proteins (hom) family is a small protein family including the $\mathrm{C}$-terminal hydrophobic motif and signal sequences of outer membrane proteins. The hom family is one of the outer-membranes coding gene family that is divided into two families: hom $A$ and $\operatorname{hom} B$ which are $90 \%$ identical; the difference is related to central domain [9].

Recent studies on adherence features of $H$. pylori have reported that $b a b A$ promotes attachment of $H$. pylori to the gastric epithelial cells. The $b a b A$ facilitates entry of cagA and $v a c A$ virulence factors into host cells $[10,11]$.

The second adhesion is $s a b A$ first identified in the $b a b A$ mutant H. pylori strain [8]. The $s a b A$ binds to sialylated carbohydrates on the surface of neutrophils. From this perspective, $s a b A$ is thought to promote immune response [11].

The aim of this study was to determine $H$. pylori babA, $h o m B, a s p A$, and $s a b A$ genes and to identify the rate of these virulence genes in the biopsy samples by PCR analysis.

\section{Materials and Methods}

2.1. Collection of Biopsy Samples. A total of 214 patients were included in this study: 115 nonulcer dyspepsia and 99 peptic ulcer. The patients were from south east part of Turkey undergoing upper gastrointestinal endoscopy at the endoscopy unit of the Department of Gastroenterology, University of Gaziantep. During endoscopy, biopsy samples were taken and the obtained tissues were placed into $0.8 \%$ serum physiologic solution and then cultured immediately. Informed consent was taken from all patients and The Ethics Committee of Medical School of University of Gaziantep approved the study. Results were confirmed both clinically and microbiologically.

\subsection{Microbiologic Analysis}

2.2.1. Culturing. In order to prevent contamination, aseptic conditions were provided. The obtained tissues were immediately placed into a liquid $0.8 \%$ serum physiologic solution and inoculated into Columbia agar with $5 \%$ sheep blood (BD, Heidelberg, Germany), containing H. pylori selective supplement (OXOID LTD, Basingstoke, Hampshire, England) to eliminate another bacterial contamination, and then incubated under anaerobic conditions, $5 \% \mathrm{CO}_{2}$ at $37^{\circ} \mathrm{C}$ for 4-6 days.

2.2.2. Urease, Catalase, and Oxidase Tests. To prove existence of $H$. pylori, catalase (Merck, Darmstadt, Germany), urease (Merck, Darmstadt, Germany), and oxidase (Merck, Darmstadt, Germany) tests were performed and also H. pylori morphology was identified.

2.2.3. Gram-Staining. To observe $H$. pylori under the light microscope, gram staining method was performed. Crystal violet (Merck, Darmstadt, Germany) was applied to heatfixed smear of bacterial culture. Lugol (Merck, Darmstadt, Germany) that binds crystal violet was added. To decolorize it, ethanol (Merck, Darmstadt, Germany) was added and then stained with safranin (Merck, Darmstadt, Germany).

\subsection{Genotyping of $H$. pylori}

2.3.1. DNA Isolation. Genomic DNA was extracted from histopathologically confirmed cases of nonulcer dyspepsia and peptic ulcer using Qiagen DNA isolation kit Qiagen, QIAmp DNA Mini Kit (Hilden, Germany) according to manufacturer's instructions. The DNA was stored at $-20^{\circ} \mathrm{C}$ until used for molecular studies.

2.3.2. PCR Analysis. Touchdown PCR protocols were performed using Dream Taq DNA Polymerase (Thermo Scientific, Lithuania, EU) kit. PCR amplifications were performed on $50 \mu \mathrm{l}$ master mixture that contained $100 \mathrm{ng}$ of genomic DNA, 10 pmole each of primers, $10 \mathrm{X}$ buffer, $2 \mathrm{mM}$ each of nucleotides (Deoxynucleotide Triphosphate, Thermo Scientific, Lithuania, EU), and 0.5 units of Taq Polymerase. PCR annealing temperatures for primers of aspA, babA, cagA, homB, sabA, and vacA were $59^{\circ} \mathrm{C}, 55^{\circ} \mathrm{C}, 58^{\circ} \mathrm{C}, 58^{\circ} \mathrm{C}, 56^{\circ} \mathrm{C}$, and $55^{\circ} \mathrm{C}$, respectively. PCR products were then electrophoresed for $45 \mathrm{~min}$ at 130 Volt on $1 \%$ agarose gel in the presence of $0.5 \mathrm{~g} / \mathrm{mL}$ of ethidium bromide (Sigma, Steinheim, Germany) and illuminated under UV light (UVP EC3 imaging system, Upland, CA, USA).

2.3.3. Statistical Analysis. Comparisons of variables were performed with the chi-square test, One-way ANOVA test, and Tukey's Multiple Comparison Test (GraphPad Prism 5) to compare the differences among nonulcer dyspepsia and peptic ulcer patients. $p$ values $<0.05$ were considered significant.

\section{Results}

Gastric biopsies from all patients included in the study were cultured and initially assessed for the presence of $H$. pylori by urease, catalase, and oxidase tests. As a result of these tests, $H$. pylori were detected in 82 patients $(38.32 \%)$, whereas bacteria could not be detected in 132 patients $(61.68 \%)$. All H. pyloripositive patients (82) were further analyzed for the presence of $H$. pylori virulence factors by PCR using babA, hom $B$, asp $A$, and sabA-specific primers encoding (Table 1(a)) babA, homB, $\operatorname{asp} A$, and $s a b A$ genes (Figure 1).

A total of $82 \mathrm{H}$. pylori-positive patients (46 nonulcer dyspepsia (25 females, 21 males) and 36 peptic ulcer (16 females, 20 males)) were enrolled in this study (Table 1(b)). The mean age of the overall population was $45.7 \pm 16.5$ years. There were significant relationships between gender and 
TABLE 1: Oligonucleotide primers and sizes of the PCR products for virulence factors of $H$. pylori.

(a)

\begin{tabular}{|c|c|c|c|c|}
\hline Primer & Primer sequence & Annealing Temperature $\left({ }^{\circ} \mathrm{C}\right)$ & Primer Length & Product Size (bp) \\
\hline AspA-F & ATGCGTATGGAGCATGATTTCATT & 55.9 & 24 & 1401 \\
\hline AspA-R & TTTATGCTTTTTGAAAGCGTGAGGGCTT & 62.2 & 28 & \\
\hline BabA-F & ATGAAAAAACACATCCTTTCATTA & 52.5 & 24 & 2192 \\
\hline BabA-R & TTATTCAAATACACGCTATAGAGTCTT & 57.4 & 27 & \\
\hline CagA-F & AATACACCAACGCCTCCAAG & 57.3 & 20 & 1741 \\
\hline CagA-R & GCTGACAAAGGAGCACTTCC & 59.4 & 20 & \\
\hline HomB-F & TACAGACGCTCAAGGCAATG & 57.3 & 20 & 1005 \\
\hline HomB-R & TCTATGGGTAGGGCGTTTTG & 57.3 & 20 & \\
\hline SabA-F & CTCTCTCTCGCTTGCGGTAT & 59.4 & 20 & 187 \\
\hline SabA-R & TTGAATGCTTTGCCTCAATG & 53.2 & 20 & \\
\hline VacA-F & ACAAACACACCGCAAAATCA & 53.2 & 20 & 1624 \\
\hline VacA-F & AACGGCCACATTAGTGGAAG & 57.3 & 20 & \\
\hline
\end{tabular}

(b)

\begin{tabular}{lccccccccc}
\hline Gender & Kind of disease & Number of patients & AspA+ & BabA+ & CagA+ & HomB+ & SabA+ & VacA+ & Mean Age \\
\hline \multirow{2}{*}{ Male } & NS & 21 & 16 & 3 & 2 & 1 & 2 & 4 & $39.85 \pm 17.11$ \\
& GU & 20 & 15 & 6 & 0 & 0 & 1 & 6 & $49.4 \pm 17.82$ \\
\multirow{3}{*}{ Female } & NS & 25 & 18 & 5 & 1 & 1 & 3 & 4 & $47.52 \pm 17.01$ \\
& GU & 16 & 9 & 3 & 0 & 1 & 0 & 6 & $45.93 \pm 12.28$ \\
\hline
\end{tabular}

(c)

\begin{tabular}{lcccc}
\hline & NS & GU & Total & $p$ value \\
\hline Number of patients & 46 & 36 & 82 & - \\
AspA & $34(73.91 \%)$ & $25(69.44 \%)$ & $59(71.95 \%)$ & \\
BabA & $7(15.21 \%)$ & $9(25 \%)$ & $16(19.51 \%)$ & ns \\
CagA & $3(6.52 \%)$ & $0(0 \%)$ & $3(3.65 \%)$ & $\mathrm{ns}$ \\
HomB & $2(4.34 \%)$ & $1(2.77 \%)$ & $3(3.65 \%)$ & $\mathrm{ns}$ \\
SabA & $5(10.86 \%)$ & $1(2.77 \%)$ & $6(7.31 \%)$ & $\mathrm{ns}$ \\
VacA & $12(26.08 \%)$ & $8(22.22 \%)$ & $20(24.39 \%)$ & $\mathrm{ns}$ \\
\hline
\end{tabular}

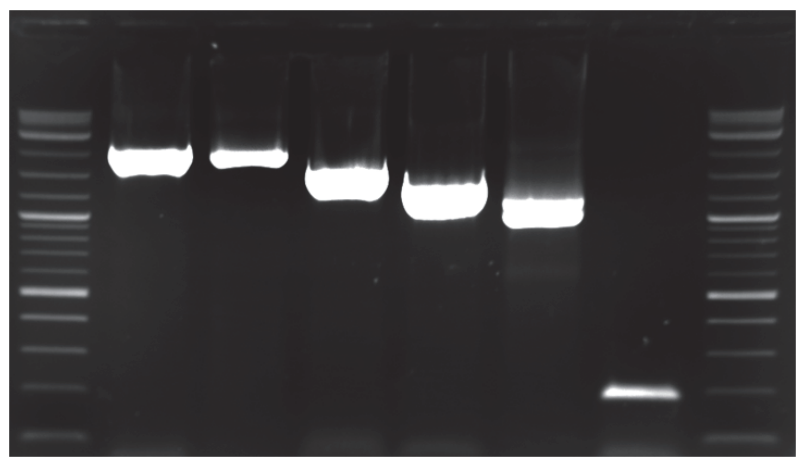

FIGURE 1: Characterization of virulence factors of $H$. pylori by PCR. Each lane shows different virulence factors of $H$. pylori strain isolated from human samples. M: Marker, A: babA (2192 bp), B: cagA (1741 bp), C: VacA (1624 bp), D: AspA (1401 bp), E: HomB (1005 bp), and F: sabA (187 bp).

the nonulcer dyspepsia and peptic ulcer diseases related to these virulence factors $(p<0.001)$. However, there were no significant differences in mean age $(p>0.05)$.

\subsection{Virulence Factors}

(i) Blood Group Antigen-Binding Adhesin, babA. The babA gene of $H$. pylori was determined in 16 patients (19.51\%), whereas 66 patients $(80.49 \%)$ were classified as $b a b A$ negative (Table $1(\mathrm{c})$ ). Out of $16 \mathrm{babA}$ gene positive patients, 7 of them (43.75\%) were from nonulcer dyspepsia patients and 9 of them $(56.25 \%)$ were from peptic ulcer patients (Table 1(b)). The presence of $b a b A$ was statistically significant in nonulcer dyspepsia $(p<0.001)$ and peptic ulcer $(p<0.001)$ (Table 2(b)) (Figures 2(a)-2(g)).

(ii) Helicobacter Outer Membrane Family Member, homB. The 1005-bp PCR product indicating the presence of homB gene was detected in 3 patients $(3.66 \%)$, whereas 79 patients (96.34\%) were negative for homB gene (Table 2(a)). Out of 3 homB-positive strains, 2 isolates $(66.6 \%)$ were from nonulcer dyspepsia patient and 1 isolate $(33.3 \%)$ was from patient diagnosed with peptic ulcer disease. The presence of homB was associated with the presence of aspA $(p<0.001)$ and $b a b A(p<0.05)$ (Table $2(a))$. A statistically significant correlation between homB and $a s p A$ and $b a b A$ gene was 
TABLE 2: Comparison and statistical analysis of $H$. pylori virulence factors.

(a)

\begin{tabular}{lcc}
\hline Comparison & $p$ value & $95 \%$ CI \\
\hline CagA vs HomB & $\mathrm{ns}$ & -0.18 to 0.13 \\
CagA vs SabA & $\mathrm{ns}$ & -0.14 to 0.16 \\
CagA vs AspA & $<0.0001$ & 0.50 to 0.81 \\
CagA vs BabA & $<0.05$ & 0.002 to 0.31 \\
CagA vs VacA & $<0.05$ & 0.002 to 0.314 \\
HomB vs SabA & $\mathrm{ns}$ & -0.11 to 0.19 \\
HomB vs AspA & $<0.0001$ & 0.52 to 0.83 \\
HomB vs BabA & $<0.05$ & 0.02 to 0.33 \\
HomB vs VacA & $<0.05$ & 0.02 to 0.33 \\
SabA vs AspA & $<0.0001$ & 0.49 to 0.80 \\
SabA vs BabA & $\mathrm{ns}$ & -0.009 to 0.302 \\
SabA vs VacA & $\mathrm{ns}$ & -0.009 to 0.302 \\
AspA vs BabA & $<0.0001$ & -0.65 to -0.34 \\
AspA vs VacA & $<0.0001$ & -0.65 to -0.34 \\
BabA vs VacA & $\mathrm{ns}$ & -0.15 to 0.15 \\
\hline
\end{tabular}

(b)

\begin{tabular}{lcc}
\hline & NS & GU \\
\hline AspA & $<0.0001$ & $<0.0001$ \\
BabA & $<0.001$ & $<0.001$ \\
CagA & $<0.001$ & $>0.05$ \\
HomB & $<0.001$ & $<0.001$ \\
SabA & $<0.001$ & $<0.001$ \\
VacA & $<0.001$ & $<0.001$ \\
\hline
\end{tabular}

detected. Moreover, the status of homB had significant effect on nonulcer dyspepsia $(p<0.001)$ and peptic ulcer patients $(p<0.001)$ (Figure 2(d)) (Figures 2(a)-2(g))

(iii) Aspartate Ammonia-Lyase, aspA. Fifty-nine biopsies that were obtained from different patients $(71.94 \%)$ were positive for the aspA gene, with the remaining 23 (28.04\%) being aspA-negative as a result of the 1401-bp PCR product (Table 1(c)). Out of 59 aspA-positive strains, 34 isolates (57.62\%) were from nonulcer dyspepsia patients, and 25 isolates (42.38\%) were from patients diagnosed with peptic ulcer disease. The frequency of aspA $(71.95 \%)(p<0.0001)$ was significantly higher compared to the frequency of $b a b A$ (19.51\%), homB (3.65\%), and sabA (7.31\%) in nonulcer dyspepsia and peptic ulcer patients. The presence of aspA was associated with the presence of $b a b A$, homB, and $s a b A(p<$ 0.0001 ) (Table 2(a)). There was a positive correlation between $a s p A$ and $b a b A, h o m B, s a b A$, and $v a c A$ genes. The presence of aspA had statistically significant impact on nonulcer dyspepsia $(p<0.001)$ and peptic ulcer $(p<0.001)$ (Table 2(b)) (Figures 2(a)-2(g)).

(iv) Sialic Acid-Binding Adhesin, SabA. The 187-bp PCR product indicating the presence of $s a b A$ gene of $H$. pylori was determined in 6 patients $(7.31 \%)$, whereas 76 patients $(92.69 \%)$ were classified as sabA-negative (Table 1(c)). Out of 6 sabA-positive patients, 5 of them (83.33\%) were from nonulcer dyspepsia patients and 1 of them $(16.66 \%)$ was from peptic ulcer patient. The presence of $s a b A$ was just associated with the presence of aspA $(\mathrm{p}<0.001)$. Furthermore, the presence of sabA gene had significant effect on nonulcer dyspepsia $(p<0.001)$ and peptic ulcer $(p<0.001)$ (Table 2(b)) (Figure 2(f)).

Possible combinations of all of these virulence factors were determined in Turkish population (Figures $2(\mathrm{a})-2(\mathrm{~g})$ ).

\section{Discussion}

H. pylori is a gram-negative bacillus which causes gastritis, peptic ulcer, and gastric cancer [12]. The prevalence of $H$. pylori depends on geographic regions, age, social and economic status, occupation, and living environment $[6,13]$. $H$. pylori have genetically diverse strains, and the strains differ in virulence [14].

In this study, the distribution of aspA, babA, homB, and $s a b A$ genes in $H$. pylori isolated from patients suffering from gastroduodenal diseases in Turkey determined using PCR analysis and the relationship between these virulence factors was assessed.

Studies have reported that there is a relationship between $b a b A$-positive $H$. pylori and gastric inflammation in humans. Furthermore, the babA-positive $H$. pylori increased risk of peptic ulcer and gastric cancer in humans $[15,16]$.

The $b a b A$ gene has been detected on the outer membrane of the $H$. pylori strain. It has been shown that the $b a b A$ is able to induce DNA double-strand breaks (DSBs) in the cells, but DSBs are the strictest type of DNA destruction and can cause chromosomal aberrations, such as deletions, insertions, and translocations resulting in loss of heterozygosity which are hallmarks of gastric cancer [17].

H. pylori strains that were isolated from East Asia expressed $b a b A$ gene but $H$. pylori strains from 24 western countries did not express $b a b A$ gene. These bacterial strains caused mild gastric problem. A meta-analysis review revealed that the existence of $b a b A$ is correlated with high risk of peptic ulcer $(\mathrm{OR}=2.069)$, especially the duodenal ulcer $(\mathrm{OR}=$ $1.588)$. This type of association was observed only in Western countries and not in Asian countries [18].

During the first 2-12 weeks during the experimental $H$. pylori infection, the babA expression disappeared in the experimental animals $[19,20]$.

H. pylori that was isolated from patient samples showed incredible variety at the $b a b A$ locus, which can translate distinct adhesin that binds only blood group $\left(\mathrm{O} / \mathrm{Le}^{\mathrm{b}}\right.$, or $\mathrm{A} / \mathrm{ALe}^{\mathrm{b}}$ and $\mathrm{B} / \mathrm{BLe}^{\mathrm{b}}$ ) [21].

We have also observed the same results as documented in literatures. The babA expression is a dynamic process. The vigorous and variety nature of host glycosylation adds extra complexity. It has been shown that loss of babA expression associated with gender. For this conclusion, the mice model has been used [22]. The oor A, scoD, aroQ, fld $A$, and aspA of $H$. pylori proteins are thought to hypothetically interact. It is deduced that these proteins also play a role in oxidation reduction [23]. 


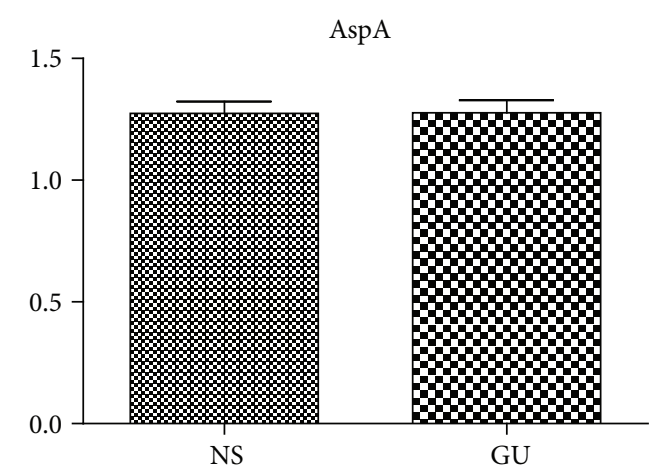

(a)

VacA

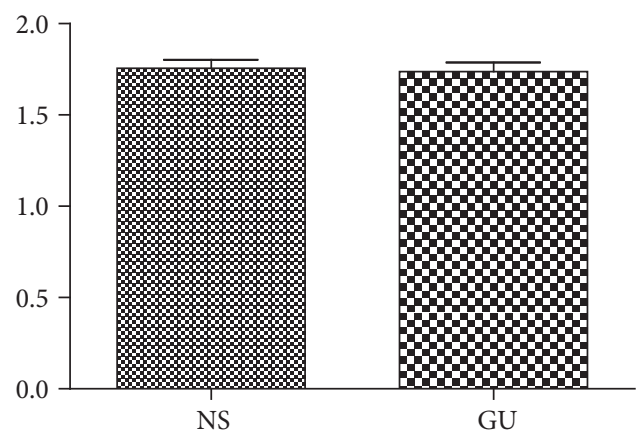

(c)

CagA

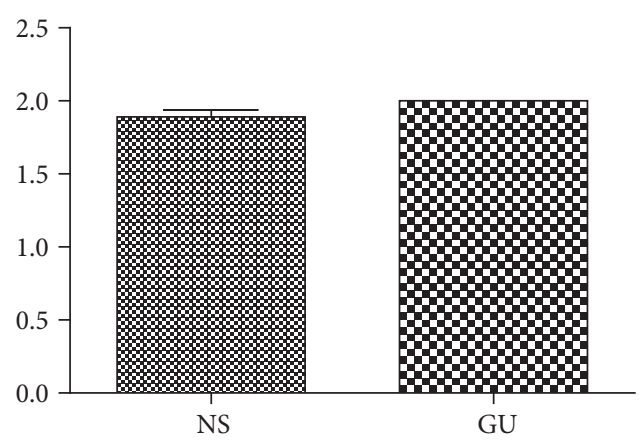

(e)

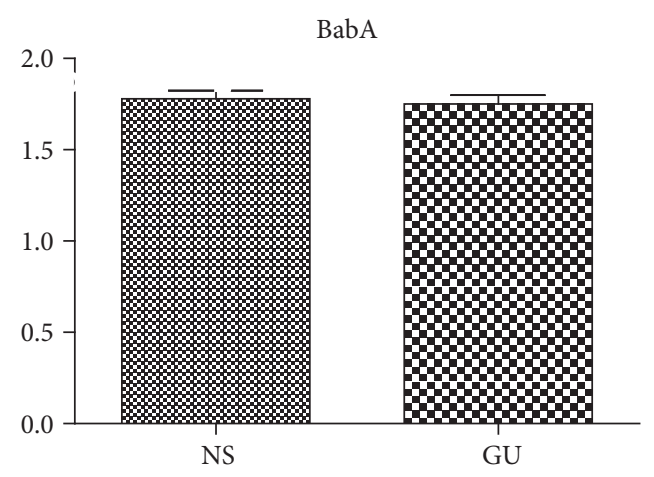

(b)

HomB

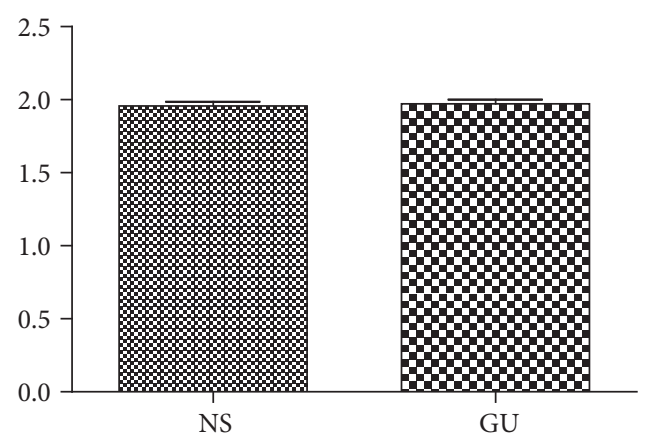

(d)

SabA

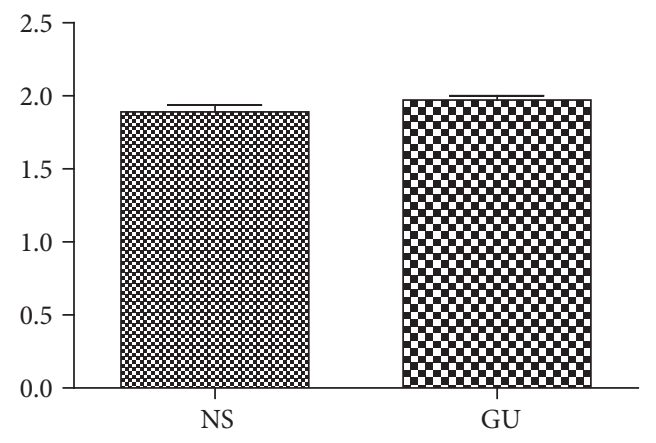

(f)

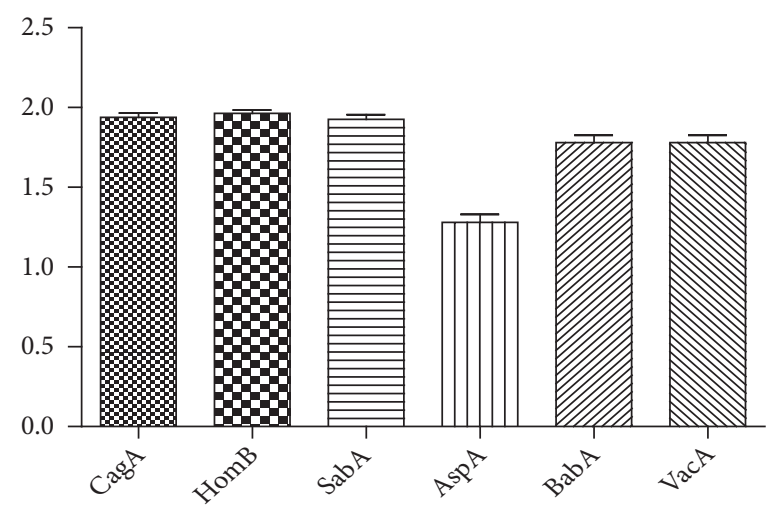

(g)

FIGURE 2: PCR application of the biopsy samples taken from $\mathrm{H}$. pylori positive patients with nonulcer and gastric ulcer samples. The presence of AspA (a), BabA (b), VacA (c), HomB (d), CagA (e), and SabA (f) genes in nonulcer and gastric ulcer samples by using PCR. (g) The comparison of $H$. pylori virulence factors in normal and gastric ulcer samples. 
Significant increase in protein with antioxidant activity (aroQ, aspA, fldA, icd, Oor A, and $s c o B$ ) and high acid environment adaptation proteins (kat $A$ and napa) in $H$. pylori has been shown to be high [23]. It has been shown that an increase in the expression of three genes encoding enzymes involved in intrabacterial ammonia production was observed. The genes are amidase $a m i E$ and $a m i F$ and $a s p A$. These enzymes can help neutralize the protons entering under acidic environmental conditions by producing intrabacterial ammonia. This study revealed that aspA is taking part in intrabacterial ammonia production [24].

The cytotoxin-associated gene $(\operatorname{cag} A)$ and vacuolating cytotoxin (vacA) are $H$. pylori virulence factors and associated with gastric ulcer, gastric cancer $[25,26]$. However, it has been documented that there is no difference between the presence of the homB gene and severe gastric diseases [27]. Besides, the disease reason has been correlated with many outer membrane proteins (OMPs). Particularly, the outer membrane proteins of $\mathrm{H}$. pylori such as alp $A, \operatorname{alp} B, b a b A$, hom $B$, hopZ, oip $A$, and $s a b A$ are all correlated with variable disease outcomes [28]. H. pylori has a high content of simple sequence repeats, mainly in genes encoding outer membrane proteins [29]. The cagA and vacA are polymorphic genes. The outer membrane proteins families are strictly correlated paralogs. For instance, the bab- genes family consists of three paralogs $b a b A, b a b B$, and $b a b C$. These paralog $H$. pylori genes can be located at three different chromosomal loci [30].

During infection and an increase of $H$. pylori colonization, $\operatorname{hom} B$, outer membrane protein, is very crucial for adherence of the $H$. pylori to the gastric epithelium. A statistically significant correlation between homB and aspA ( $p$ $<0.0001)$ and $b a b A(p<0.05)$ gene was detected in this study. On the other hand, there was no significant relationship between homB and $s a b A$ gene according to this study [31].

The hom gene family is a small paralogous protein. The hom $\mathrm{B}$ and hom $\mathrm{A}$ genes are almost the same which are $90 \%$ [24]. The hom $\mathrm{B}$ was observed more often than hom $\mathrm{A}$ in East Asia. The homB was correlated with an enlarged risk of peptic ulcer disease in East Asia. The homB has a role in proinflammation. The homB was important for bacterial attachment to host cell surface [9].

There are many different adhesion components existing on $H$. pylori to bind carbohydrates. The $s a b A$ has vital and important role in the primary colonization of $H$. pylori. $H$. pylori sabA proteins are also taking part in stable infections and development of chronic inflammation which directs to tissue damage [32].

H. pylori sabA is a diversity gene. The $s a b A$ gene has been associated with different stomach diseases such as $100 \%$ in gastric cancer, $86.7 \%$ in gastric ulcer, and $83.3 \%$ in gastritis and duodenal ulcer [33].

In conclusion, virulence factors of $H$. pylori gene sequences might differ markedly from other regions or other countries. These differences are detectable by PCR analysis and sequencing. These data suggest that virulence factor variants may present new markers for other factors involved in gastric carcinogenesis or probably influencing the result of H. pylori infection [34].

\section{Data Availability}

The data used to support the findings of this study are available from the corresponding author upon request.

\section{Disclosure}

The authors have no relevant financial or nonfinancial relationships to disclose.

\section{Conflicts of Interest}

The authors declare that there are no actual or potential conflicts of interest related to this article.

\section{Acknowledgments}

This project was supported by the Scientific Research Project Unit of the University of Gaziantep.

\section{References}

[1] H. Mobley, "The role of Helicobacter pylori urease in the pathogenesis of gastritis and peptic ulceration," Alimentary Pharmacology \& Therapeutics, vol. 10, supplement 1, pp. 57-64, 1996.

[2] R. H. Hunt, S. D. Xiao, F. Megraud et al., "Helicobacter pylori in developing countries. World Gastroenterology Organisation Global Guideline," Journal of Gastrointestinal and Liver Diseases, vol. 20, no. 3, pp. 299-304, 2011.

[3] J. Ferlay, I. Soerjomataram, R. Dikshit et al., "Cancer incidence and mortality worldwide: sources, methods and major patterns in GLOBOCAN 2012," International Journal of Cancer, vol. 136, no. 5, pp. E359-E386, 2015.

[4] S. Suerbaum and P. Michetti, "Helicobacter pylori infection," The New England Journal of Medicine, vol. 347, no. 15, pp. 1175-1186, 2002.

[5] S. Shiota, R. Suzuki, and Y. Yamaoka, "The significance of virulence factors in Helicobacter pylori," Journal of Digestive Diseases, vol. 14, no. 7, pp. 341-349, 2013.

[6] F. Wang, W. Meng, B. Wang, and L. Qiao, "Helicobacter pylori-induced gastric inflammation and gastric cancer," Cancer Letters, vol. 345, no. 2, pp. 196-202, 2013.

[7] D. Ilver, A. Arnqvist, J. Ögren et al., "Helicobacter pylori adhesin binding fucosylated histo-blood group antigens revealed by retagging," Science, vol. 279, no. 5349, pp. 373-377, 1998.

[8] J. Mahdavi, B. Sondén, M. Hurtig et al., "Helicobacter pylori SabA adhesin in persistent infection and chronic inflammation," Science, vol. 297, no. 5581, pp. 573-578, 2002.

[9] N. R. Hussein, "A study of Helicobacter pylori outer-membrane proteins (hom) A and B in Iraq and Turkey," Journal of Infection and Public Health, vol. 4, no. 3, pp. 135-139, 2011.

[10] M. Rugge, R. M. Genta, F. Di Mario et al., "Gastric cancer as preventable disease," Clinical Gastroenterology and Hepatology, vol. 15, no. 12, pp. 1833-1843, 2017.

[11] Y. Yamaoka, "Roles of Helicobacter pylori BabA in gastroduodenal pathogenesis," World Journal of Gastroenterology, vol. 14, no. 27, pp. 4265-4272, 2008.

[12] M. C. Mommersteeg, J. Yu, M. P. Peppelenbosch, and G. M. Fuhler, "Genetic host factors in Helicobacter pylori-induced 
carcinogenesis: Emerging new paradigms," Biochimica et Biophysica Acta (BBA) - Reviews on Cancer, vol. 1869, no. 1, pp. 4252, 2018.

[13] A. Y. Wang and D. A. Peura, "The prevalence and incidence of Helicobacter pylori-associated peptic ulcer disease and upper gastrointestinal bleeding throughout the world," Gastrointestinal Endoscopy Clinics of North America, vol. 21, no. 4, pp. 613635, 2011.

[14] N. Ishijima, M. Suzuki, H. Ashida et al., "BabA-mediated adherence is a potentiator of the Helicobacter pylori type IV secretion system activity," The Journal of Biological Chemistry, vol. 286, no. 28, pp. 25256-25264, 2011.

[15] Y. Yamaoka, S. Kikuchi, H. M. T. ElZimaity, O. Gutierrez, M. S. Osato, and D. Y. Graham, "Importance of Helicobacter pylori oipA in clinical presentation, gastric inflammation, and mucosal interleukin 8 production," Gastroenterology, vol. 123, no. 2, pp. 414-424, 2002.

[16] S. Fujimoto, O. Olaniyi Ojo, A. Arnqvist et al., "Helicobacter pylori BabA expression, gastric mucosal injury, and clinical outcome," Clinical Gastroenterology and Hepatology, vol. 5, no. 1, pp. 49-58, 2007.

[17] I. M. Toller, K. J. Neelsen, M. Steger et al., "Carcinogenic bacterial pathogen Helicobacter pylori triggers DNA doublestrand breaks and a DNA damage response in its host cells," Proceedings of the National Acadamy of Sciences of the United States of America, vol. 108, no. 36, pp. 14944-14949, 2011.

[18] M.-Y. Chen, C.-Y. He, X. Meng, and Y. Yuan, "Association of Helicobacter pylori babA2 with peptic ulcer disease and gastric cancer," World Journal of Gastroenterology, vol. 19, no. 26, pp. 4242-4251, 2013

[19] J. V. Solnick, L. M. Hansen, N. R. Salama, J. K. Boonjakuakul, and M. Syvanen, "Modification of Helicobacter pylori outer membrane protein expression during experimental infection of rhesus macaques," Proceedings of the National Acadamy of Sciences of the United States of America, vol. 101, no. 7, pp. 21062111, 2004.

[20] C. M. Styer, L. M. Hansen, C. L. Cooke et al., "Expression of the BabA adhesin during experimental infection with Helicobacter pylori," Infection and Immunity, vol. 78, no. 4, pp. 1593-1600, 2010.

[21] M. Aspholm-Hurtig, G. Dailide, M. Lahmann et al., "Functional adaptation of $\mathrm{BabA}$, the $\mathrm{H}$. pylori $\mathrm{ABO}$ blood group antigen binding adhesin," Science, vol. 305, no. 5683, pp. 519-522, 2004.

[22] M. E. Kable, L. M. Hansen, C. M. Styer et al., "Host determinants of expression of the helicobacter pylori BabA adhesin," Scientific Reports, vol. 7, no. 1, Article ID 46499, 2017.

[23] V. De Re, O. Repetto, S. Zanussi et al., "Protein signature characterizing Helicobacter pylori strains of patients with autoimmune atrophic gastritis, duodenal ulcer and gastric cancer," Infectious Agents and Cancer, vol. 12, no. 1, article no. 22, 2017.

[24] D. R. Scott, E. A. Marcus, Y. Wen, J. Oh, and G. Sachs, "Gene expression in vivo shows that Helicobacter pylori colonizes an acidic niche on the gastric surface," Proceedings of the National Acadamy of Sciences of the United States of America, vol. 104, no. 17, pp. 7235-7240, 2007.

[25] J. Gwack, A. Shin, C.-S. Kim et al., "CagA-producing Helicobacter pylori and increased risk of gastric cancer: A nested casecontrol study in Korea," British Journal of Cancer, vol. 95, no. 5, pp. 639-641, 2006.

[26] L. E. Torres, K. Melián, A. Moreno et al., "Prevalence of vacA, cagA and babA2 genes in Cuban Helicobacter pylori isolates,"
World Journal of Gastroenterology, vol. 15, no. 2, pp. 204-210, 2009.

[27] A. Kim, S. L. Servetas, J. Kang et al., "Helicobacter pylori bab paralog distribution and association with cagA, vacA, and homA/B genotypes in american and south korean clinical isolates," PLoS One, vol. 10, no. 8, Article ID e0137078, 2015.

[28] A. Talebi Bezmin Abadi, T. Taghvaei, A. Mohabbati Mobarez, G. Vaira, and D. Vaira, "High correlation of babA2-positive strains of Helicobacter pylori with the presence of gastric cancer," Internal and Emergency Medicine, vol. 8, no. 6, pp. 497-501, 2013.

[29] A. Åberg, P. Gideonsson, A. Vallström et al., "A Repetitive DNA element regulates expression of the helicobacter pylori sialic acid binding adhesin by a rheostat-like mechanism," PLoS Pathogens, vol. 10, no. 7, Article ID e1004234, 2014.

[30] R. I. Armitano, M. J. Matteo, C. Goldman et al., "Helicobacter pylori heterogeneity in patients with gastritis and peptic ulcer disease," Infection, Genetics and Evolution, vol. 16, pp. 377-385, 2013.

[31] J. Kang, K. R. Jones, S. Jang et al., "The geographic origin of Helicobacter pylori influences the association of the homB gene with gastric cancer," Journal of Clinical Microbiology, vol. 50, no. 3, pp. 1082-1085, 2012.

[32] H. Ota, J. Nakayama, M. Momose et al., "Helicobacter pylori infection produces reversible glycosylation changes to gastric mucins," Virchows Archiv, vol. 433, no. 5, pp. 419-426, 1998.

[33] Z. Pakbaz, M. H. Shirazi, R. Ranjbar et al., "Frequency of sabA gene in helicobacter pylori strains isolated from patients in Tehran, Iran," Iranian Red Crescent Medical Journal, vol. 15, no. 9, pp. 767-770, 2013.

[34] Y. Yamaoka, T. Kodama, K. Kashima, D. Y. Graham, and A. R. Sepulveda, "Variants of the 3' region of the cagA gene in Helicobacter pylori isolates from patients with different $\mathrm{H}$. pylori-associated diseases," Journal of Clinical Microbiology, vol. 36, no. 8, pp. 2258-2263, 1998. 


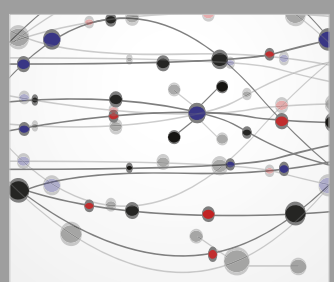

The Scientific World Journal
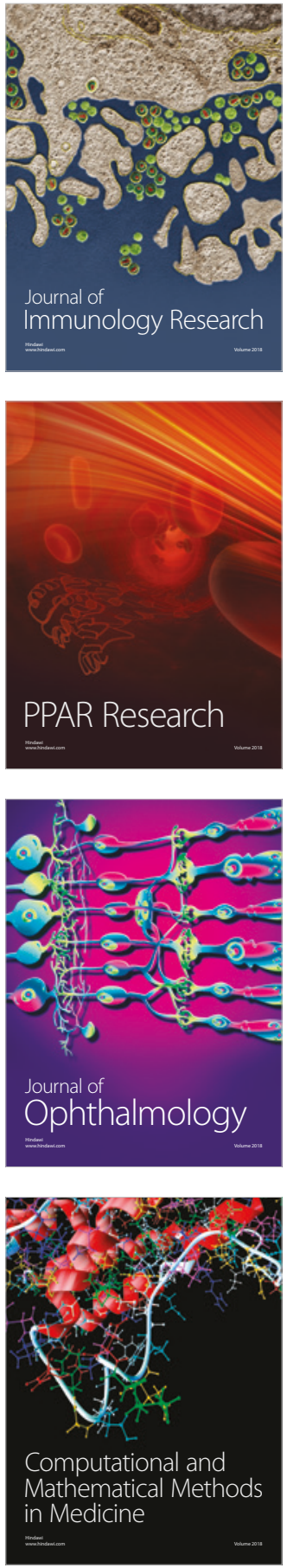

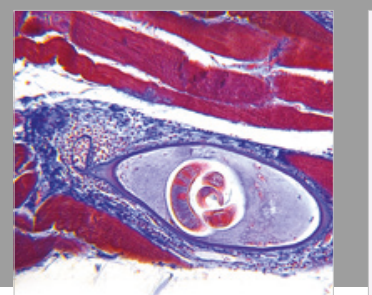

Gastroenterology Research and Practice

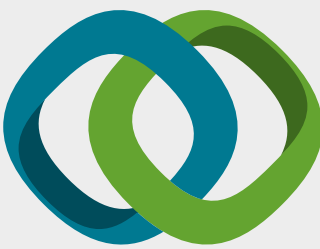

\section{Hindawi}

Submit your manuscripts at

www.hindawi.com
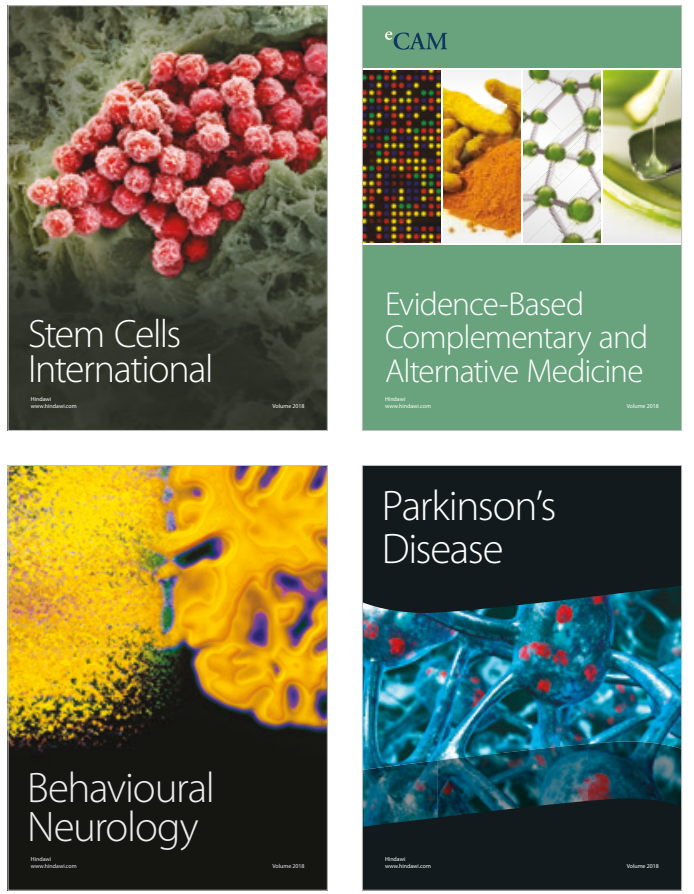

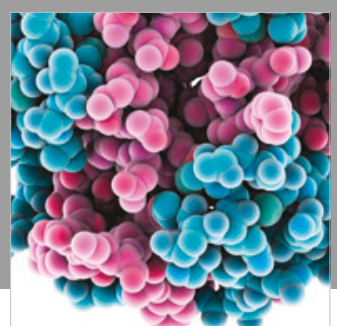

ournal of

Diabetes Research

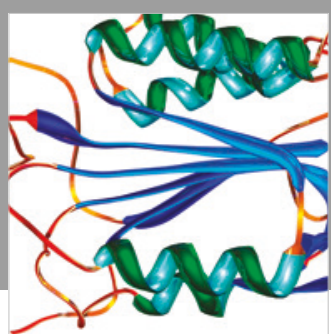

Disease Markers
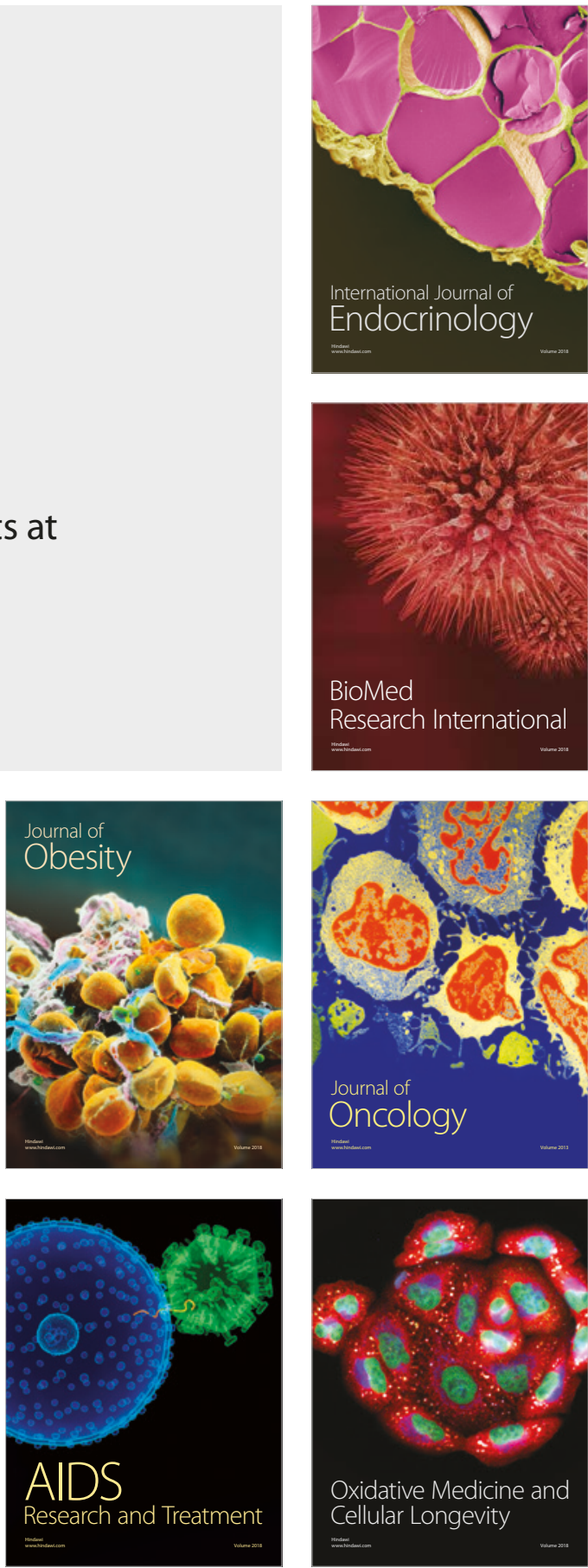